\title{
Stress degradation studies and development of stability-indicating TLC-densitometry method for determination of prednisolone acetate and chloramphenicol in their individual and combined pharmaceutical formulations
}

\author{
Syed Ghulam Musharraf ${ }^{1 *}$, Urooj Fatima ${ }^{2}$ and Rahat Sultana ${ }^{2}$
}

\begin{abstract}
A rapid and reproducible stability indicating TLC method was developed for the determination of prednisolone acetate and chloramphenicol in presence of their degraded products. Uniform degradation conditions were maintained by refluxing sixteen reaction mixtures for two hours at $80^{\circ} \mathrm{C}$ using parallel synthesizer including acidic, alkaline and neutral hydrolysis, oxidation and wet heating degradation. Oxidation at room temperature, photochemical and dry heating degradation studies were also carried out. Separation was done on TLC glass plates, pre-coated with silica gel 60F-254 using chloroform: methanol (14:1 v/v). Spots at $R_{\mathrm{f}} 0.21 \pm 0.02$ and $R_{\mathrm{f}} 0.41$ \pm 0.03 were recognized as chloramphenicol and prednisolone acetate, respectively. Quantitative analysis was done through densitometric measurements at multiwavelength $\left(243 \mathrm{~nm}, \lambda_{\max }\right.$ of prednisolone acetate and $278 \mathrm{~nm}, \boldsymbol{\lambda}_{\max }$ of chloramphenicol), simultaneously. The developed method was optimized and validated as per ICH guidelines. Method was found linear over the concentration range of 200-6000 ng/spot with the correlation coefficient $\left(r^{2} \pm S\right.$. D.) of $0.9976 \pm 3.5$ and $0.9920 \pm 2.5$ for prednisolone acetate and chloramphenicol, respectively. The developed TLC method can be applied for routine analysis of prednisolone acetate and chloramphenicol in presence of their degraded products in their individual and combined pharmaceutical formulations.
\end{abstract}

Keywords: Chloramphenicol, Prednisolone acetate, Stability-indicating TLC-densitometry, Stress degradation

\section{Introduction}

Prednisolone acetate (1), is a corticosteroid, used in polychemotherapy of cancer and also as an immunosuppressive to treat allergic disorders and hypersensitivity reactions $[1,2]$. Chloramphenicol $(2)$, an antibiotic, possesses broad spectrum antibacterial activity and is used for the treatment of rickettsial and chlamydial diseases, gram + ve and gram -ve bacterial infections and topically for superficial conjunctivial infections [3]. A number of corticosteroid and antibiotic combinations are frequently used as antibacterial agents to cure infections particularly associated with the eye. These combinations

\footnotetext{
*Correspondence: musharraf1977@yahoo.com

'H.E.J. Research Institute of Chemistry, International Center for Chemical and Biological Sciences (ICCBS), University of Karachi, Karachi-75270, Pakistan Full list of author information is available at the end of the article
}

are available in different formulations including eye ointment, eye drops and ophthalmic suspensions. Ophthalmic preparations of prednisolone acetate along with chloramphenicol are widely practiced for the treatment of superficial eye infections. However, this combination is not official with British Pharmacopoeia or US Pharmacopoeia. Many analytical methods have been reported for the determination of prednisolone acetate in cosmetics, Chinese medicinal preparations, human serum, urine and pharmaceutical preparations [4-6]. HPLC and UPLC methods are also reported for the estimation of chloramphenicol in aquatic products, pharmaceutical preparations, cosmetics comedo cream, blood, gastric contents, urine, tissues and cerebrospinal fluid [7-11]. 
Simultaneous determination of prednisolone, chloramphenicol and a degraded product, 2- amino-1-(4-nitrophenyl)propane-1,3-diol in ophthalmic solutions through HPLC is also reported [12]. Few HPTLC methods have also been reported for the determination of chloramphenicol in combination with benzocaine and 2amino-1-(4-nitrophenyl) propane-1,3-diol (ANPD), and for different corticosteroids including hydrocortisone, hydrocortisone acetate, prednisolone, betamethasone-17valerate, prednisolone sodium phosphate, dexamethasone sodium phosphate and betamethasone sodium phosphate [13]. No report for the simultaneous determination of prednisolone acetate and chloramphenicol in the presence of their degraded products through TLCdensitometry has been found so far.

Intensive consideration and attention is being paid to the development of TLC-densitometry stability-indicating assay as it is fast, reliable and accurate and involves simultaneous analysis of many samples by using small quantity of mobile phase, thus minimizing analysis time and cost per analysis. Stress testing provides evidence that how the quality of a drug substance varies with time under the influence of various environmental factors (temperature, light, humidity, etc.) and helps to establish shelf life and recommended storage conditions for the drug [14].

Taking ICH guidelines Q1A in consideration, present study describes a simple and a validated TLC-densitometry method [15] for the simultaneous determination of prednisolone acetate and chloramphenicol in presence of their degraded products formed under the applied stress conditions. As all the pharmaceutical products are supposed to be assayed for potency, a validated TLC-densitometry method, demonstrating no interferences of degraded products with the drug active components can be useful in measuring these components in routine analysis.

\section{Experimental}

Standards, prednisolone acetate (1) and chloramphenicol (2), (Figure 1), were complementarily provided by Santa (Pvt.) Ltd, Karachi, Pakistan. Pharmaceutical products including prednisolone acetate eye drops (P1, Ophtha

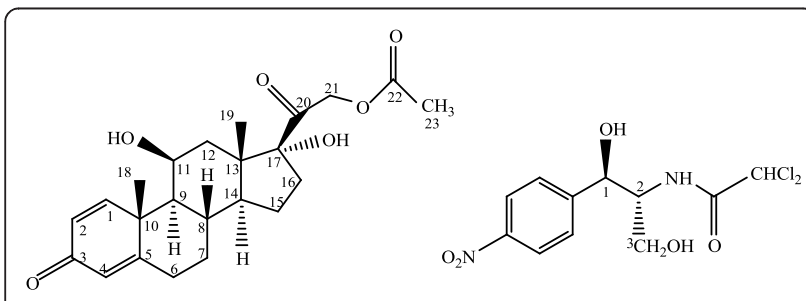

Figure 1 Structures of prednisolone acetate (1) and chloramphenicol (2).
Pred, Schazoo; P2, Mildo Pred, Remington; P3, Predforte, Barrette Hodgson; P4, Pred +, Schazoo; P5, Prens, Vega), chloramphenicol eye drops ( $\mathrm{C} 1$, spersinicol, Novartis; C2, chloroptic, Barrette Hodgson) and capsule (C3, chlormycetin, Pfizer), and ophthalmic suspensions containing prednisolone acetate and chloramphenicol in combination (PC1, prednisynth, Schazoo; PC2, prednicol, Remington) along with two expired pharmaceutical products (EC1, spersinicol, Novartis; EPC1, prednisynth, Schazoo) were purchased from local pharmacy shop, Karachi, Pakistan. Methanol and chloroform of analytical grade were purchased from the Fisher Scientific (UK). Deionized water was obtained from Millipore Milli Q Plus System (Bedford, USA). Sodium hydroxide was purchased from BioM Laboratories (Cerritos, USA) while hydrochloric acid $(\mathrm{HCl})$ and hydrogen peroxide $\left(\mathrm{H}_{2} \mathrm{O}_{2}, 35 \% \mathrm{v} / \mathrm{v}\right)$ were obtained from Fisher Scientific (UK).

\section{Instrumentation and chromatographic system}

Stress degradation studies were performed using parallel synthesizer (Smart Start Synthesizer, Chem Speed Ltd., Switzerland) with sixteen reaction vessels. Planar chromatography was performed by spotting the sample on TLC glass plate, pre-coated with silica gel 60F-254 $(20 \times$ $10 \mathrm{~cm}$ ) with the aid of CAMAG microliter sample syringe using CAMAG automatic TLC Linomat V applicator (Muntenz, Switzerland). A constant sample application rate of $0.1 \mu \mathrm{L} / \mathrm{s}$ was adopted and the distance between the two bands was $6 \mathrm{~mm}$. $15 \mathrm{~mL}$ of mobile phase (chloroform: methanol, 14:1 v/v) was used for linear ascending development and chromatogram was allowed to move to a distance of $8 \mathrm{~cm}$, in twin trough glass chamber (CAMAG). The chamber saturation time for mobile phase was 8 minutes at $25 \pm 2^{\circ} \mathrm{C}$ with relative humidity $42 \pm 5 \%$. The developed TLC plate was dried with the help of air dryer for $4 \mathrm{~min}$. Densitometric scanning was performed on CAMAG Reprostar scanner III in the reflectance absorbance mode at multiwavelength $\left(\lambda_{\max }, 243 \mathrm{~nm}\right.$ for prednisolone acetate and $\lambda_{\max }, 278 \mathrm{~nm}$ for chloramphenicol) by utilizing deuterium lamp as the source of radiation. Quantitative evaluation was performed via peak areas by WinCats software (version 1.2.3). Densitometric scanning parameters were as follows: bandwidth: $10 \mathrm{~mm}$, slit width: $0.45 \mathrm{~mm}$, slit length: $5 \mathrm{~mm}$, scanning speed: 10 $\mathrm{mm} / \mathrm{s}$.

\section{Preparation of standard solutions and pharmaceutical samples}

Three stock solutions were prepared by dissolving 100 mg of each prednisolone acetate and chloramphenicol in $100 \mathrm{~mL}$ methanol, individually and in combination. Working standard solutions were prepared by dilution 
of stock solution with methanol to give solutions in concentration range of $30-1000 \mu \mathrm{g} / \mathrm{mL}$ for calibration curve. Six-point calibration curve was formed by spotting $6 \mu \mathrm{L}$ of each standard solution in concentration range of 200$6000 \mathrm{ng} /$ spot containing both components, each concentration was spotted thrice on six replicate plates. For sample preparation, $1 \mathrm{~mL}$ ophthalmic samples (P1, P2, P3 and P4) containing $10 \mathrm{mg}$ of prednisolone acetate were diluted in $20 \mathrm{~mL}$ volumetric flasks with methanol, separately. Similarly, $1 \mathrm{~mL}$ of spersinicol and chloroptic containing $0.5 \%$ chloramphenicol was diluted in $10 \mathrm{~mL}$ volumetric flasks with methanol. Chloramphenicol capsules, equivalent to $2500 \mathrm{mg}$ (chlormycetin) were placed in $500 \mathrm{~mL}$ of volumetric flask and after addition of 100 $\mathrm{mL}$ water, heated on steam bath till the capsules weredisintegrated. After further addition of $300 \mathrm{~mL}$ water, it was again heated on steam bath with mixing. After cooling to room temperature, it was diluted to volume with water. $5 \mathrm{~mL}$ of the resulting solution was transferred to $100 \mathrm{~mL}$ volumetric flask and diluted with methanol $[16,17]$. $1 \mathrm{~mL}$ ophthalmic samples (prednisynth and prednicol) containing $5 \mathrm{mg}$ of prednisolone acetate and 2 mg chloramphenicol were diluted in $10 \mathrm{~mL}$ volumetric flasks with methanol $[4,12]$. In similar manner, solutions for expired spersinicol and prednisynth were also prepared ( $1 \mathrm{~mL}$ in $10 \mathrm{~mL}$ volumetric flask). $6 \mu \mathrm{L}$ of each sample was applied on TLC plate for chromatographic analysis.

\section{Method validation}

The developed method was validated as per the requirements of the ICH guidelines. Linearity was evaluated by determining six standard working solutions at a concentration 200-6000 ng/spot. Peak area and concentration was subjected to the least square linear regression equation to calculate the regression data and correlation coefficients. In order to calculate $\mathrm{S} / \mathrm{N}$ ratio for LOD and LOQ, the formulae used were $3.3 \delta / \mathrm{S}$ and $10 \delta / \mathrm{S}$, respectively where $\delta$ is the residual error and $S$ stands for slope of calibration curve. In order to check the robustness, following parameters were deliberately changed within the range of $\pm 5 \%$ at three different concentration levels (200, 400 and $800 \mathrm{ng}$ ); amount of mobile phase, mobile phase composition, time from spotting to chromatography, time from chromatography to scanning and chamber saturation time. Intra-day and inter-day precisions were determined with the standards and degraded reaction mixtures. For method repeatability, assay at three different concentration levels (200, 400 and $800 \mathrm{ng}$ ) was repeatedly performed six times on the same day (intra-day). For reproducibility, same samples at three concentration levels (200, 400 and $800 \mathrm{ng}$ ) were analyzed in different days (inter-day) and results were statistically evaluated in terms of \% R.S.D. For recovery studies, pre analyzed pharmaceutical drugs containing prednisolone acetate (P1), chloramphenicol (C1) and both in combination (PC1) were spiked with extra 25 , 50 and $75 \%$ of prednisolone acetate and chloramphenicol. The specificity of the proposed method was analyzed by overlapping the densitogram of the standard and samples and comparing it at peak start, peak apex and peak end positions.

\section{Preparation of forced degradation products}

Methanolic stock solutions $(1 \mathrm{mg} / \mathrm{mL})$ of both prednisolone acetate (set 1) and chloramphenicol (set 2) were prepared, separately and in combination (set 3 ) to perform forced degradation studies in parallel synthesizer by refluxing the reaction mixtures for two hours at $80^{\circ}$ C. After the reactions were completed, all the solutions were preserved at $-80^{\circ} \mathrm{C}$ till analysis. Average peak areas of active components were analyzed after triplicate analysis.

For acidic hydrolysis, $1 \mathrm{~N}$ and $5 \mathrm{~N} \mathrm{HCl}$ were used, for alkaline hydrolysis, $0.1 \mathrm{~N}, 1 \mathrm{~N}$ and $5 \mathrm{~N} \mathrm{NaOH}$ were used while for neutral hydrolysis Milli Q water was used. 3 $\mathrm{mL}$ of each concentration of acidic and alkaline solutions and Milli Q water were added into $3 \mathrm{~mL}(1 \mathrm{mg} /$ $\mathrm{mL})$ stock solutions of all three sets. To study wet heating degradation, $3 \mathrm{~mL}(1 \mathrm{mg} / \mathrm{mL})$ of stock solution of each set 1 , set 2 and set 3 was subjected to degradation. Oxidation was carried out by adding $1 \mathrm{~mL}$ of $\mathrm{H}_{2} \mathrm{O}_{2}$ $(35 \% \mathrm{v} / \mathrm{v})$ in $3 \mathrm{~mL}$ stock solution of each set. All the resultant solutions were refluxed for two hours at $80^{\circ} \mathrm{C}$ in parallel synthesizer. $1 \mu \mathrm{L}(500 \mathrm{ng} / \mathrm{spot})$ of $1 \mathrm{~N} \mathrm{HCl}$, $0.5 \mu \mathrm{L}(250 \mathrm{ng} / \mathrm{spot})$ of $5 \mathrm{~N} \mathrm{HCl}, 4 \mu \mathrm{L}$ (2000 ng/spot) of $0.1 \mathrm{~N}, 1 \mathrm{~N}$ and $5 \mathrm{~N} \mathrm{NaOH}$ treated solutions, $4 \mu \mathrm{L}(2000$ $\mathrm{ng} / \mathrm{spot})$ of neutral hydrolysis, $6 \mu \mathrm{L}$ (6000 ng/spot) from wet heat degradation mixture and $4 \mu \mathrm{L}(3000 \mathrm{ng} / \mathrm{spot})$ from oxidation mixture were applied on TLC plate in triplicate for chromatographic analysis.

Dry heat degradation was conducted by taking standard prednisolone acetate and chloramphenicol and heated in oven at $90^{\circ} \mathrm{C}$ for 4 hrs. $1 \mathrm{mg}$ of each treated standard was dissolved in $1 \mathrm{~mL}$ of methanol and $4 \mu \mathrm{L}$ (4000 ng/spot) of resultant solution of each, prednisolone acetate, chloramphenicol and both in combination was applied on TLC plate in triplicate for chromatographic analysis. For oxidation reaction at room temperature, $3 \mathrm{~mL}$ stock solution of each set was added with $1 \mathrm{~mL}$ of $\mathrm{H}_{2} \mathrm{O}_{2}(35 \% \mathrm{v} / \mathrm{v})$ and the resultant solutions were kept for 24 hours at room temperature. $4 \mu \mathrm{L}(3000$ $\mathrm{ng}$ /spot) of each treated solution was applied on TLC plate in triplicate for chromatographic analysis. In order to evaluate photochemical degradation of prednisolone acetate, chloramphenicol and both in combination, stock solution of each set was directly exposed to the sunlight for three days from 8 to $18 \mathrm{hrs}$ at $30 \pm 2^{\circ} \mathrm{C} .6$ 
$\mu \mathrm{L}$ (6000 ng/spot) of each treated solution was applied on TLC plate in triplicate for chromatographic analysis.

\section{Results and discussion}

Optimization of TLC system and method validation

With the aim to develop a reliable stability indicating method, solvent system was optimized with standards, samples and degraded products. Different solvent systems of 2-propanol, toluene, ether, chloroform, methanol, glacial acetic acid and acetone were tried in varying ratios. Solvent systems and resulting $R_{\mathrm{f}}$ values of both standards are summarized in Table S1 [see Additional file 1]. Most of the solvent systems showed diffused spots of prednisolone acetate. Suitable separation with best resolution was achieved with chloroform: methanol (14: $1 \mathrm{v} / \mathrm{v})$ which showed sharp bands with $R_{\mathrm{f}}$ value of chloramphenicol at $0.21 \pm 0.02$ and of prednisolone acetate at $0.41 \pm 0.03$ (Figure 2).

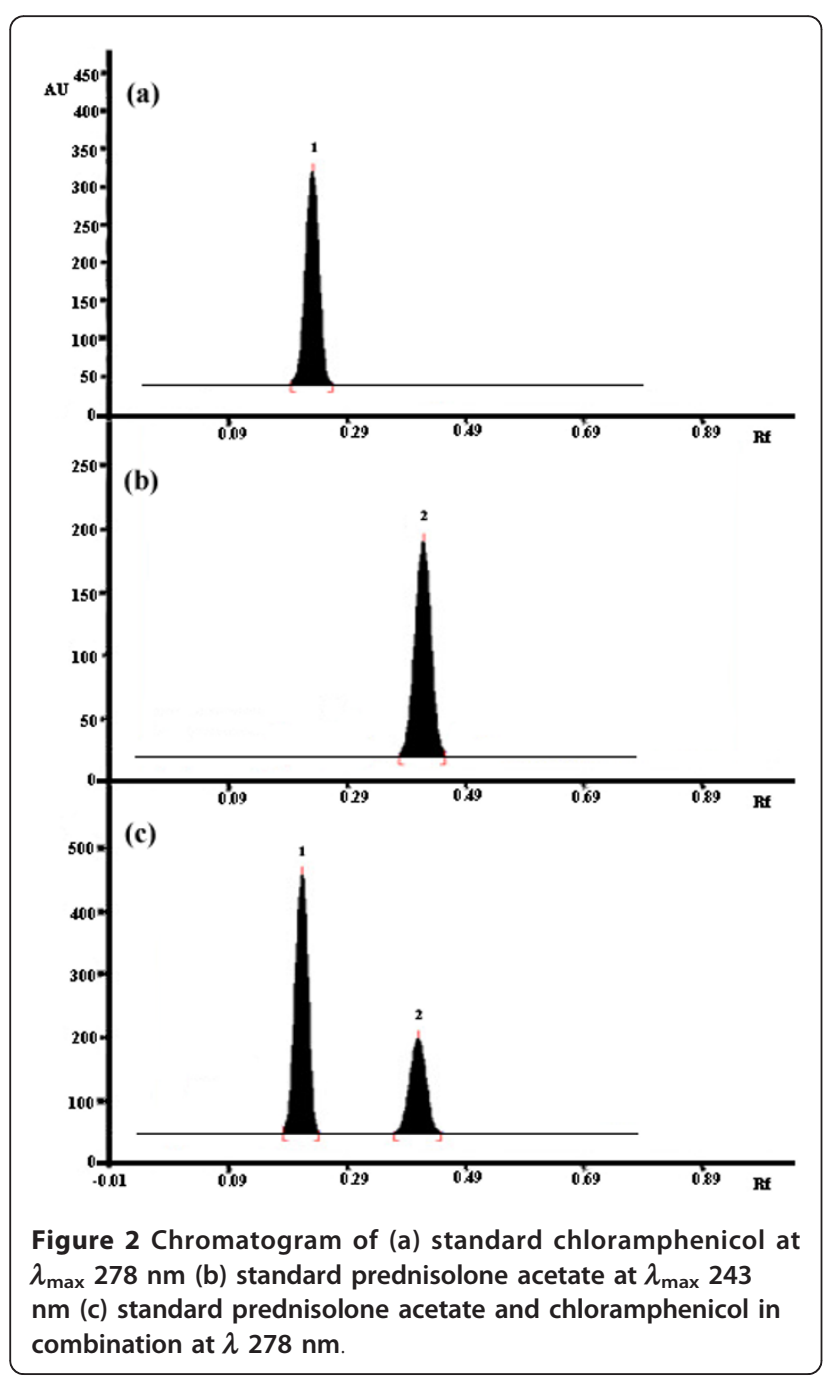

Standard calibration curve for both prednisolone acetate and chloramphenicol in the concentration range of 200$6000 \mathrm{ng}$ was found linear with $r^{2} \pm$ S.D. $0.9966 \pm 3.5$ and $0.9920 \pm 2.5$, respectively. For Intra-day and interday precision, \% R.S.D. observed for prednisolone acetate was 1.32 and 3.90, respectively while for chloramphenicol, 1.09 and 1.68, respectively. For prednisolone acetate and chloramphenicol, LODs were found to be 4.77 and $3.00 \mathrm{ng} / \mu \mathrm{L}$, respectively while LOQs were found to be 14.46 and $9.12 \mathrm{ng} / \mu \mathrm{L}$, respectively. For robustness analysis, the S.D. of peak area of standard levels (200, 400 and $800 \mathrm{ng}$ ) was estimated for each parameter. S.D. was 1.07 and 3.9 for changing the amount of mobile phase, 2.48 and 2.70 for varying in mobile phase composition, 0.95 and 2.96 for varying time from spotting to chromatography, 0.56 and 1.09 for varying time from chromatography to scanning and 1.53 and 1.32 for varying chamber saturation time for prednisolone acetate and chloramphenicol, respectively. SD for peak areas were calculated and summarized in Table S2 [see Additional file 1]. Spiking studies showed recovery of prednisolone acetate (98-104\%) and chloramphenicol (93-101\%) from their pharmaceutical products (Table S3 [see Additional file 1]). Peak purity was estimated by comparing the peak positions of both prednisolone acetate and chloramphenicol in standard spectra with those in reaction solutions. Good correlation, $r^{2}$ (start, middle) $=0.999$ and $r^{2}$ (middle, end $)=$ 0.9999 was observed by comparing the spectra of standard and samples, in both cases. The linear regression data and the method validation results are summarized in Table 1.

\section{Stability indicating property in prednisolone acetate}

$76.2 \%$ of prednisolone acetate was decomposed in $1 \mathrm{~N} \mathrm{HCl}$ and $100 \%$ in $5 \mathrm{~N} \mathrm{HCl}$. Three additional peaks at $R_{\mathrm{f}} 0.01$,

Table 1 Linear regression data and validation parameters of prednisolone acetate (1) and chloramphenicol (2).

\begin{tabular}{|c|c|c|}
\hline Parameters & $\begin{array}{l}\text { Prednisolone } \\
\text { acetate } \\
\text { (at } \lambda_{\max } 243 \mathrm{~nm} \text { ) }\end{array}$ & $\begin{array}{l}\text { Chloramphenicol } \\
\text { (at } \lambda_{\max } 278 \mathrm{~nm} \text { ) }\end{array}$ \\
\hline Linearity range & 200-6000 ng/spot & 200-6000 ng/spot \\
\hline $\begin{array}{l}\text { Correlation coefficient, } r^{2} \pm \\
\text { SD }\end{array}$ & $0.9966 \pm 3.5$ & $0.9920 \pm 2.5$ \\
\hline Slope \pm SD & $2.42 \pm 0.5$ & $2.74 \pm 0.34$ \\
\hline Intercept \pm SD & $1106 \pm 0.48$ & $4183 \pm 2.15$ \\
\hline$Y=m x+c$ & $2.42 x+1106$ & $2.738 x+4183$ \\
\hline Intra-day $(\mathrm{n}=3), \%$ RSD & 1.32 & 1.09 \\
\hline Inter-day $(n=3), \%$ RSD & 3.90 & 1.68 \\
\hline Limit of detection & $4.77 \mathrm{ng} / \mu \mathrm{L}$ & $3.0 \mathrm{ng} / \mu \mathrm{L}$ \\
\hline Limit of quantification & $14.46 \mathrm{ng} / \mu \mathrm{L}$ & $9.12 \mathrm{ng} / \mu \mathrm{L}$ \\
\hline Robustness & Robust & Robust \\
\hline Specificity & Specific & Specific \\
\hline
\end{tabular}


0.03 , and 0.29 were commonly generated in both acidic reaction mixtures. In addition to those peaks, three additional peaks at $R_{\mathrm{f}} 0.17,0.19$ and 0.73 were only generated in $1 \mathrm{~N} \mathrm{HCl}$ reaction mixture while four additional peaks at $R_{\mathrm{f}} 0.02,0.58,0.78$ and 0.80 were only obtained under strong acidic condition (5N HCl). Moreover, $100 \%$ degradation was observed under alkaline conditions. Degraded peaks were observed at $R_{\mathrm{f}} 0.01,0.02$ and 0.50 . In addition to common peaks, some additional peaks were also observed. Three peaks were at $R_{\mathrm{f}} 0.17,0.36$ and 0.78 in $0.1 \mathrm{~N} \mathrm{NaOH}$, and peaks at $R_{\mathrm{f}} 0.03$ and 0.29 in $1 \mathrm{~N}$ and $5 \mathrm{~N}$ $\mathrm{NaOH}$ treated solutions, respectively. Prednisolone acetate showed $77.3 \%$ degradation by neutral hydrolysis with four additional peaks at $R_{\mathrm{f}} 0.01,0.02,0.17$ and 0.29 . Prednisolone acetate degradations under wet and dry heating were 95.8 and $18.5 \%$, respectively. Both conditions showed common degraded peaks at $R_{\mathrm{f}} 0.01,0.17,0.26$ and 0.47 , while additional peaks were observed at $R_{\mathrm{f}} 0.29,0.46$ and 0.80 for wet heating and $R_{\mathrm{f}} 0.78$ for dry heating conditions. Both oxidation mixtures, refluxed for 2 hours at $80^{\circ} \mathrm{C}$ and 24 hours at room temperature, showed $21.05 \%$ and $5.47 \%$ degradation, respectively with three common peaks at $R_{\mathrm{f}}$ $0.05,0.14$, and 0.29 . Under photochemical conditions, $100 \%$ degradation was observed with the degraded peaks at $R_{\mathrm{f}} 0.01,0.29,0.33,0.47,0.58$, and 0.73 .

Prednisolone acetate showed greater degradation susceptibility to acidic, alkaline and neutral hydrolyses, wet heating and photochemical conditions. Total eighteen degraded products were observed under various stress conditions with some common and different peaks. Peaks with higher $R_{\mathrm{f}}$ values indicated less polar nature than prednisolone acetate. A common degraded product with $R_{\mathrm{f}} 0.01$ was attributed to all the stress conditions except oxidation reaction. Degraded product with $R_{\mathrm{f}} 0.02$ was only generated by acidic $(5 \mathrm{~N} \mathrm{HCl})$, alkaline $(0.1,1$ and $5 \mathrm{~N} \mathrm{NaOH}$ ) and neutral hydrolysis. Peak at $R_{\mathrm{f}} 0.03$ was generated under acidic $(1$ and $5 \mathrm{~N} \mathrm{HCl})$ and alkaline $(1 \mathrm{~N} \mathrm{NaOH})$ hydrolysis while peaks at $R_{\mathrm{f}} 0.05$ and 0.14 were only obtained by oxidation reaction. Degraded product at $R_{\mathrm{f}} 0.17$ was commonly generated by acidic ( $1 \mathrm{~N}$ $\mathrm{HCl})$, alkaline $(0.1 \mathrm{~N} \mathrm{NaOH})$ and neutral hydrolysis and wet and dry heating degradation, while peak at $R_{\mathrm{f}} 0.26$ was only found in wet and dry heating conditions. Peak at $R_{\mathrm{f}} 0.29$ was found in various stress conditions including acidic ( 1 and $5 \mathrm{~N} \mathrm{HCl}$ ), alkaline $(1$ and $5 \mathrm{~N} \mathrm{NaOH})$ and neutral hydrolysis, wet heating, oxidation and photo degradation. Peaks at $R_{\mathrm{f}} 0.33$ and 0.36 are the characteristic peaks of photo degradation and alkaline hydrolysis $(0.1 \mathrm{~N} \mathrm{NaOH})$, respectively. Similarly peak at $R_{\mathrm{f}} 0.46$ was only generated in wet heat degradation reaction, while a peak with $R_{\mathrm{f}} 0.47$ was observed in wet and dry heating and photo degradation conditions. Degraded product at $R_{\mathrm{f}} 0.58$ was generated by acidic hydrolysis $(5 \mathrm{~N} \mathrm{HCl})$ and photo degradation. Peak with $R_{\mathrm{f}} 0.73$ was found in acidic hydrolysis $(1 \mathrm{~N} \mathrm{HCl})$ and photo degradation. Degraded peak at $R_{\mathrm{f}} 0.78$ was commonly generated by acidic hydrolysis $(5 \mathrm{~N} \mathrm{HCl})$, alkaline hydrolysis $(0.1 \mathrm{~N} \mathrm{NaOH})$ and dry heating. Degraded product at $R_{\mathrm{f}} 0.80$ was generated through acidic hydrolysis $(5 \mathrm{~N} \mathrm{HCl})$ and wet heating degradation. Stress degradation study of prednisolone acetate is summarized in Table 2. Chromatograms of stress degraded products obtained from prednisolone acetate are shown in Figures 3 and 4 while video densitogram pictures are shown in Figure 5.

\section{Stability indicating property in chloramphenicol}

Chloramphenicol was $23.7 \%$ degraded in $1 \mathrm{~N} \mathrm{HCl}$ and $69.3 \%$ in $5 \mathrm{~N} \mathrm{HCl}$. Common degraded peaks were observed at $R_{\mathrm{f}} 0.01$ and 0.04 , while in strong acidic medium an additional peak generated at $R_{\mathrm{f}} 0.81$. Under alkaline conditions, chloramphenicol was $100 \%$ degraded and a common degraded peak at $R_{\mathrm{f}} 0.01$ was also generated. Under all alkaline conditions, additional degraded products were observed at $R_{\mathrm{f}} 0.44$ and 0.79 , while peaks at $R_{\mathrm{f}} 0.81$ were found in $1 \mathrm{~N} \mathrm{NaOH}$ treated solution. Three additional peaks at $R_{\mathrm{f}} 0.02,0.04$ and 0.48 were found in $5 \mathrm{~N} \mathrm{NaOH}$ treated solution. A single degraded product was found under neutral hydrolysis at $R_{\mathrm{f}} 0.01$. In wet and dry heat degradation conditions, two common additional peaks were found at $R_{\mathrm{f}} 0.01$ and 0.79 . Under oxidation conditions, three additional peaks at $R_{\mathrm{f}}$ $0.01,0.12$ and 0.31 were generated, while seven

\section{Table 2 Summary of stress degradation studies of prednisolone acetate (1)}

\begin{tabular}{|c|c|c|}
\hline $\begin{array}{l}\text { Degradation } \\
\text { conditions }\end{array}$ & $\begin{array}{l}\% \\
\text { Degradation }\end{array}$ & $R_{\mathrm{f}}$ of degraded products \\
\hline \multicolumn{3}{|l|}{ Acidic hydrolysis $^{a}$} \\
\hline $1 \mathrm{~N} \mathrm{HCl}$ & 76.26 & $0.01,0.03,0.17,0.19,0.29,0.73$ \\
\hline $5 \mathrm{~N} \mathrm{HCl}$ & 100 & $\begin{array}{l}0.01,0.02,0.03,0.29 \\
0.58,0.78,0.80\end{array}$ \\
\hline \multicolumn{3}{|l|}{ Basic hydrolysis $^{a}$} \\
\hline $0.1 \mathrm{~N} \mathrm{NaOH}$ & 100 & $0.01,0.02,0.17,0.36,0.50,0.78$ \\
\hline $1 \mathrm{~N} \mathrm{NaOH}$ & 100 & $0.01,0.02,0.03,0.29,0.50$ \\
\hline $5 \mathrm{~N} \mathrm{NaOH}$ & 100 & $0.01,0.02,0.29,0.50$ \\
\hline \multicolumn{3}{|l|}{ Neutral hydrolysis $^{a}$} \\
\hline $\mathrm{H}_{2} \mathrm{O}$ & 77.26 & $0.01,0.02,0.17,0.29$ \\
\hline Wet heating ${ }^{a}$ & 95.86 & $\begin{array}{l}0.01,0.17,0.26,0.29,0.46,0.47 \\
0.80\end{array}$ \\
\hline Dry heating & 18.566 & $0.01,0.17,0.26,0.47,0.78$ \\
\hline Photochemical & 100 & $0.01,0.29,0.33,0.47,0.58,0.73$ \\
\hline \multicolumn{3}{|l|}{ Oxidation } \\
\hline $35 \% \mathrm{v} / \mathrm{v} \mathrm{H}_{2} \mathrm{O}_{2}{ }^{\mathrm{a}}$ & 21.05 & $0.05,0.14,0.29$ \\
\hline $\begin{array}{l}\text { Oxidation at room } \\
\text { temp }\end{array}$ & 5.47 & $0.05,0.14,0.29$ \\
\hline
\end{tabular}

${ }^{\mathrm{a}}$ Reflux in parallel synthesizer for two hours at $80^{\circ} \mathrm{C}$ 


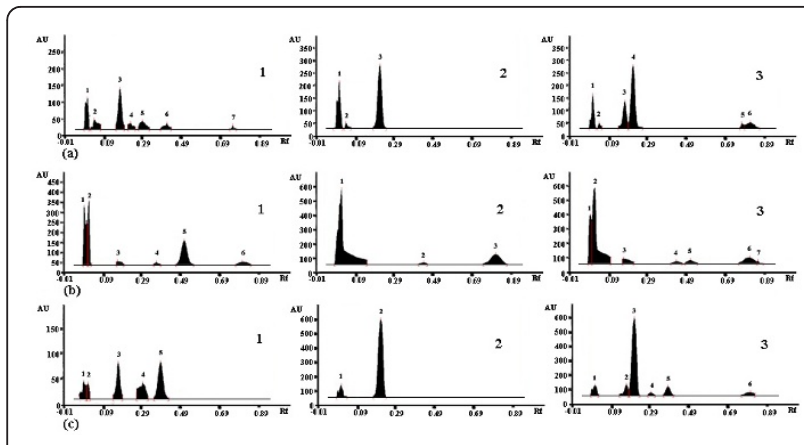

Figure 3 Chromatogram of prednisolone acetate at $\lambda_{\max } 243$ $\mathrm{nm}$ (1), chloramphenicol at $\lambda_{\max } 278 \mathrm{~nm}$ (2) and prednisolone acetate and chloramphenicol at $\lambda 278 \mathrm{~nm}$ in combination (3) subjected to (a) acidic hydrolysis $(1 \mathrm{~N} \mathrm{HCl})(b)$ alkaline hydrolysis $(0.1 \mathrm{~N} \mathrm{NaOH})($ c) neutral hydrolysis.

additional peaks at $R_{\mathrm{f}} 0.01,0.09,0.15,0.27,0.44,0.81$ and 0.85 were found by photochemical degradation.

Chloramphenicol showed more degradation to alkaline, wet heating and photochemical stress conditions. Degraded product with $R_{\mathrm{f}} 0.01$ was commonly formed under all stress conditions while degraded peak with $R_{\mathrm{f}}$ 0.02 was observed only under alkaline hydrolysis $(5 \mathrm{~N}$ $\mathrm{NaOH}$ ). Peak with $R_{\mathrm{f}} 0.04$ was generated by acidic ( 1 and $5 \mathrm{~N} \mathrm{HCl})$ and alkaline hydrolysis $(1$ and $5 \mathrm{~N} \mathrm{NaOH})$, while peak at $R_{\mathrm{f}} 0.48$ was observed only in alkaline hydrolysis (5N NaOH). Degraded products with $R_{\mathrm{f}} 0.12$ and 0.15 were found under oxidation and photo degradation conditions, respectively, while peak with $R_{\mathrm{f}} 0.31$ was formed only in oxidation reaction. Peak with $R_{\mathrm{f}} 0.44$ was generated by alkaline hydrolysis $(0.1 \mathrm{~N} \mathrm{NaOH})$ and photo degradation reactions. Degraded peak with $R_{\mathrm{f}} 0.79$ was generated by alkaline hydrolysis $(0.1 \mathrm{~N} \mathrm{NaOH})$ and wet and dry heat degradations. Degraded product with $R_{\mathrm{f}}$ 0.81 was generated by acidic hydrolysis $(5 \mathrm{~N} \mathrm{HCl})$, alkaline hydrolysis $(1 \mathrm{~N} \mathrm{NaOH})$ and photo degradation

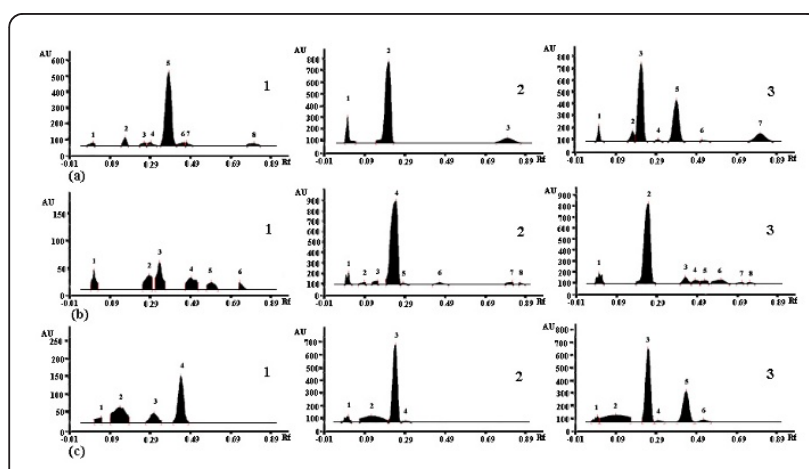

Figure 4 Chromatogram of prednisolone acetate at $\lambda_{\max } 243$ $\mathrm{nm}$ (1), chloramphenicol at $\lambda_{\max } 278 \mathrm{~nm}$ (2) and prednisolone acetate and chloramphenicol at $\lambda 278 \mathrm{~nm}$ in combination (3) subjected to (a) wet heat (b) photodegradation (c) oxidation at room temperature.

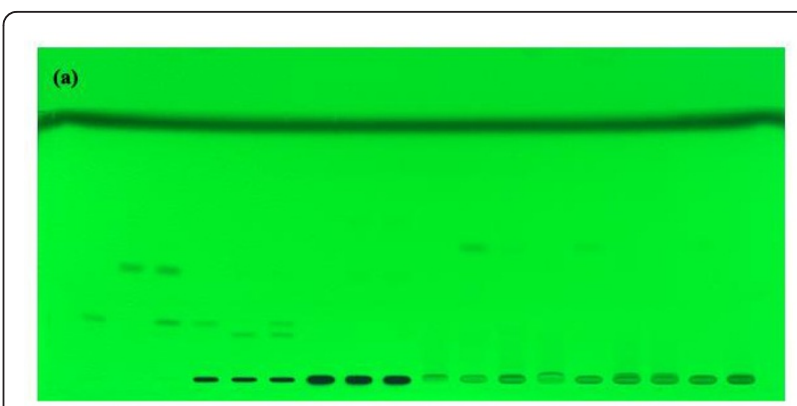

$1, \quad 2, \quad 3, \quad 4, \quad 5, \quad 6, \quad 7, \quad 8, \quad 9, \quad 10, \quad 11, \quad 12, \quad 13, \quad 14, \quad 15, \quad 16, \quad 17, \quad 18$

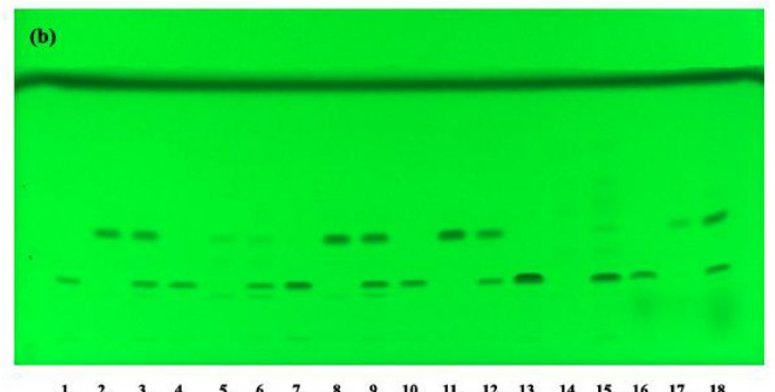

Figure 5 TLC desitometric pictures of degradation products of chloramphenicol (1), prednisolone acetate (2), chloramphenicol and prednisolone acetate in combination (3). (a) under $1 \mathrm{~N} \mathrm{HCl}$ $(4,5,6), 5 \mathrm{~N} \mathrm{HCl}(7,8,9), 0.1 \mathrm{~N} \mathrm{NaOH}(10,11,12), 1 \mathrm{~N} \mathrm{NaOH}(13,14$, 15), $5 \mathrm{~N} \mathrm{NaOH}(16,17,18)$, (b) under neutral hydrolysis $(4,5,6)$, wet heating $(7,8,9)$, dry heating $(10,11,12)$, photo degradation $(13,14$, $15)$ and oxidation at room temperature $(16,17,18)$.

conditions. Similarly peaks with $R_{\mathrm{f}} 0.09,0.27$ and 0.85 were only generated through photo degradation reaction. Stress degradation study of chloramphenicol is summarized in Table 3. Chromatograms of chloramphenicol stress degraded products are shown in Figures 3 and 4 while video densitogram pictures are shown in Figure 5.

\section{Stability indicating property of prednisolone acetate and chloramphenicol in combination}

In comparison with the individual standard solutions, a combined standards solution showed two additional peaks under acidic $(1 \mathrm{~N} \mathrm{HCl})$ condition at $R_{\mathrm{f}} 0.78$ and 0.81 while three degraded products of prednisolone acetate at $R_{\mathrm{f}} 0.03,0.19$ and 0.73 were missing. $5 \mathrm{~N} \mathrm{HCl}$ stress condition showed two additional peaks at $R_{\mathrm{f}} 0.17$ and 0.38 . Peak at $R_{\mathrm{f}} 0.81$ corresponding to the degraded product of chloramphenicol while degraded products of prednisolone acetate with $R_{\mathrm{f}} 0.03$ and 0.80 were missing. Moreover, under both acidic conditions, prednisolone acetate was $100 \%$ degraded.

Under alkaline conditions, chloramphenicol and prednisolone acetate were completely degraded. Two common additional peaks were generated under all alkaline conditions at $R_{\mathrm{f}} 0.01$ and 0.02 . Under $0.1 \mathrm{~N} \mathrm{NaOH}$ stress 
Table 3 Summary of stress degradation studies of chloramphenicol (2).

\begin{tabular}{|c|c|c|}
\hline $\begin{array}{l}\text { Degradation } \\
\text { conditions }\end{array}$ & $\begin{array}{l}\% \\
\text { Degradation }\end{array}$ & $R_{\mathrm{f}}$ of degraded products \\
\hline \multicolumn{3}{|l|}{ Acidic hydrolysis $^{a}$} \\
\hline $1 \mathrm{~N} \mathrm{HCl}$ & 23.75 & $0.01,0.04$ \\
\hline $5 \mathrm{~N} \mathrm{HCl}$ & 69.36 & $0.01,0.04,0.81$ \\
\hline \multicolumn{3}{|l|}{ Basic hydrolysis $^{a}$} \\
\hline $0.1 \mathrm{~N} \mathrm{NaOH}$ & 100 & $0.01,0.44,0.79$ \\
\hline $1 \mathrm{~N} \mathrm{NaOH}$ & 100 & $0.01,0.04,0.81$ \\
\hline $5 \mathrm{~N} \mathrm{NaOH}$ & 100 & $0.01,0.02,0.04,0.48$ \\
\hline \multicolumn{3}{|l|}{ Neutral hydrolysis ${ }^{a}$} \\
\hline $\mathrm{H}_{2} \mathrm{O}$ & 14.35 & 0.01 \\
\hline Wet heating $^{a}$ & 28.44 & $0.01,0.79$ \\
\hline Dry heating & 24 & $0.01,0.79$ \\
\hline Photochemical & 26.029 & $\begin{array}{l}\text { 0.01,0.09,0.15, } \\
0.27,0.44,0.81,0.85\end{array}$ \\
\hline \multicolumn{3}{|l|}{ Oxidation } \\
\hline $35 \% \mathrm{v} / \mathrm{v} \mathrm{H}_{2} \mathrm{O}_{2}{ }^{\mathrm{a}}$ & 4.129 & $0.01,0.12,0.31$ \\
\hline $\begin{array}{l}\text { Oxidation at room } \\
\text { temp }\end{array}$ & 9.58 & $0.01,0.12,0.31$ \\
\hline
\end{tabular}

condition, two additional peaks were found at $R_{\mathrm{f}} 0.29$ and 0.85 while chloramphenicol degraded peak at $R_{\mathrm{f}}$ 0.44 and prednisolone acetate degraded peaks at $R_{\mathrm{f}} 0.36$ and 0.78 were missing. Moreover, under $1 \mathrm{~N} \mathrm{NaOH}$ stress condition, an additional peak was observed at $R_{\mathrm{f}}$ 0.44 while chloramphenicol degraded products at $R_{\mathrm{f}}$ 0.04 and 0.81 and prednisolone acetate degraded product at $R_{\mathrm{f}} 0.50$ were missing. In $5 \mathrm{~N} \mathrm{NaOH}$ treated solution, comparison showed an additional peak at $R_{\mathrm{f}}$ 0.31 while chloramphenicol degraded products at $R_{\mathrm{f}}$ 0.04 and 0.48 and prednisolone acetate degraded products at $R_{\mathrm{f}} 0.29$ and 0.50 were missing. In neutral hydrolysis reaction mixture, an additional peak was generated at $R_{\mathrm{f}} 0.79$, while peak for prednisolone acetate at $R_{\mathrm{f}} 0.02$ was missing.

Similarly an additional degraded product at 0.50 was observed in combined sample under wet heat degradation while degraded products of prednisolone acetate at $R_{\mathrm{f}} 0.47$ and 0.80 were missing. Under dry heat degradation condition, comparison showed an additional peak at $R_{\mathrm{f}} 0.73$ while prednisolone acetate degraded peaks at $R_{\mathrm{f}} 0.17$ and 0.78 were missing. Under wet heat degradation condition, prednisolone acetate was $17 \%$ degraded while chloramphenicol was degraded up to $36.9 \%$.

For oxidation reaction, two conditions were applied, under oxidation condition 1 (refluxed for two hours at $80^{\circ} \mathrm{C}$ ), additional peak at $R_{\mathrm{f}} 0.55$ while two additional peaks at $R_{\mathrm{f}} 0.23$ and 0.55 were observed under oxidation condition 2 (reaction mixture kept for 24 hours at room temperature). Prednisolone acetate degraded peaks at $R_{\mathrm{f}}$ $0.05,0.14$ and 0.29 were missing.

Under photochemical degradation condition, additional degraded products at $R_{\mathrm{f}} 0.49,0.50$ and 0.69 were generated only in combined sample while degraded products of prednisolone acetate at $R_{\mathrm{f}} 0.29$ and 0.33 and those of chloramphenicol at $R_{\mathrm{f}} 0.09,0.15,0.28,0.44$, 0.81 and 0.85 were missing. Stress degradation study of prednisolone acetate and chloramphenicol in combined sample is summarized in Table 4 while video densitogram pictures are shown in Figures 3 and 4.

Table 4 Summary of stress degradation studies of prednisolone acetate and chloramphenicol in combination

\begin{tabular}{|c|c|c|c|}
\hline Degradation conditions & $\%$ Degradation of 1 & $\%$ Degradation of 2 & $R_{\mathrm{f}}$ of degraded products \\
\hline \multicolumn{4}{|l|}{ Acidic hydrolysis $^{a}$} \\
\hline $1 \mathrm{~N} \mathrm{HCl}$ & 100 & 31.8 & $\begin{array}{l}0.01,0.04,0.17,0.29,0.78 \\
0.81\end{array}$ \\
\hline $5 \mathrm{~N} \mathrm{HCl}$ & 100 & 82.7 & $\begin{array}{l}0.01,0.02,0.04,0.17,0.29 \\
0.38,0.58,0.78\end{array}$ \\
\hline \multicolumn{4}{|l|}{ Basic hydrolysis $^{a}$} \\
\hline $0.1 \mathrm{~N} \mathrm{NaOH}$ & 100 & 100 & $0.01,0.02,0.17,0.29,0.50,0.79,0.85$ \\
\hline $1 \mathrm{~N} \mathrm{NaOH}$ & 100 & 100 & $0.01,0.02,0.03,0.29,0.44$ \\
\hline $5 \mathrm{~N} \mathrm{NaOH}$ & 100 & 100 & $0.01,0.02,0.31$ \\
\hline \multicolumn{4}{|l|}{ Neutral hydrolysis ${ }^{a}$} \\
\hline $\mathrm{H}_{2} \mathrm{O}$ & 74.52 & 17.9 & $0.01,0.17,0.29,0.79$ \\
\hline Wet heating $^{a}$ & 17 & 36.9 & $0.01,0.17,0.29,0.50,0.79$ \\
\hline Dry heating & 0 & 0 & $0.01,0.26,0.47,0.73,0.79$ \\
\hline Photochemical & 85.808 & 17.1 & $0.01,0.47,0.49,0.50,0.58,0.69,0.73$ \\
\hline \multicolumn{4}{|l|}{ Oxidation } \\
\hline 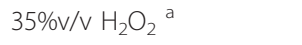 & 30.56 & 7.20 & $0.01,0.12,0.31,0.55$ \\
\hline At room temp & 9.029 & 13.4 & $0.01,0.12,0.23,0.31,0.55$ \\
\hline
\end{tabular}

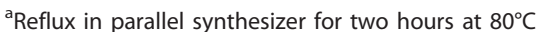




\section{Analysis of marketed samples}

In prednisolone acetate eye drops, prednisolone acetate was found 97\% (P1), 100\% (P2), 93\% (P3), 93\% (P4) and $81 \%$ (P5) of the label claim. In chloramphenicol eye drops and capsule, the \%s of chloramphenicol were found $98(\mathrm{C} 1), 95(\mathrm{C} 2)$ and $99(\mathrm{C} 3)$. In eye drops, containing prednisolone acetate and chloramphenicol in combination, the \%s of chloramphenicol were 96 (PC1) and 95 (PC2) while prednisolone acetate was found $100 \%$ in both samples. Two expired pharmaceutical products were also analyzed. In a expired sample (spersinicol), peak was not found for chloramphenicol at $R_{\mathrm{f}} 0.21$ (100\% degradation) but six degraded peaks were found at $R_{\mathrm{f}} 0.01,0.09,0.19,0.15,0.38$ and 0.58 . Stress degradation study data showed that peak with $R_{\mathrm{f}} 0.01$ was commonly formed under all stress conditions. Degraded products with $R_{\mathrm{f}} 0.09$ and 0.15 were formed by photodegrdation Degraded products with $R_{\mathrm{f}} 0.38$ and 0.58 were not found under any stress condition applied to chloramphenicol alone. Degraded product with $R_{\mathrm{f}} 0.38$ was generated in combined sample of prednisolone acetate and chloramphenicol under acidic hydrolysis $(5 \mathrm{~N}$ $\mathrm{HCl}$ ). In expired prednisynth product (light yellow in color), peak for chloramphenicol was found but with

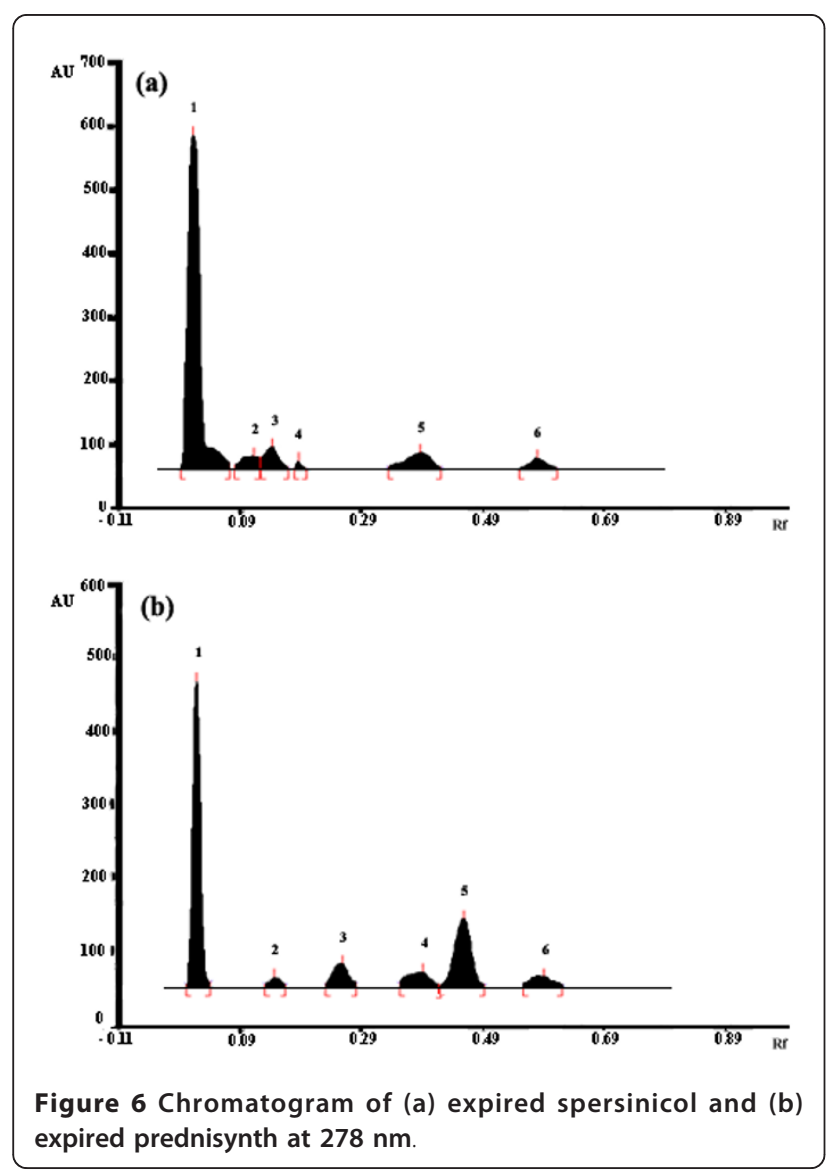

59\% degradation and prednisolone acetate was degraded up to $72.2 \%$. Five additional peaks were also found at $R_{\mathrm{f}}$ $0.01,0.15,0.26,0.38$ and 0.58 (Figure 6). Comparison showed that degraded product at $R_{\mathrm{f}} 0.01$ was a common product in both, individual and in combination. Degraded products at $R_{\mathrm{f}} 0.15$ and 0.38 were generated by the degradation of chloramphenicol. Degraded products with $R_{\mathrm{f}} 0.26$ (found under dry and wet heat degradation conditions) and 0.58 (produced under acidic hydrolysis and photo degradation) were associated with the degradation of prednisolone acetate (Table 5).

\section{Conclusions}

A validated TLC method for routine analysis to determine the stability of prednisolone acetate and chloramphenicol in pharmaceutical dosage forms has been developed. Current study demonstrates the degradation susceptibility of drugs to different stress conditions and thus helps in determining the changes in chemical, physical and microbiological properties of the drug samples with time. It also helps in understanding the mechanism and pathway of degraded products formation and in developing a profile reflecting the changes in identity, purity and potency of the product. The comparison of stress degradation in individual and combined formulations reveals the effect on \% degradation and the number of degraded products. The developed stability indicating TLC method is simple, reproducible and can be used for the simultaneous analysis of two active components (chloramphenicol and prednisolone acetate). It appears suitable for routine analysis of these components selectively in presence of their degraded products in individual and in combined pharmaceutical formulations.

Table 5 Analysis of pharmaceutical products.

\begin{tabular}{cclcl}
\hline Product & \multicolumn{2}{c}{ Prednisolone acetate } & \multicolumn{2}{c}{ Chloramphenicol } \\
\cline { 2 - 5 } & $\begin{array}{c}\text { Conc. (in } \\
\text { ng) }\end{array}$ & $\begin{array}{l}\text { \% } \\
\text { Degradation }\end{array}$ & $\begin{array}{c}\text { Conc. (in } \\
\text { ng) }\end{array}$ & $\begin{array}{l}\text { \% } \\
\text { Degradation }\end{array}$ \\
\hline P1 & 2909.94 & 3.002 & - & - \\
P2 & 3000 & 0 & - & - \\
P3 & 2778.6 & 7.38 & - & - \\
P4 & 2803.05 & 6.565 & - & - \\
P5 & 2440.5 & 18.65 & - & - \\
C1 & - & - & 2956.5 & 1.45 \\
C2 & - & - & 2850.9 & 4.97 \\
C3 & - & - & 2984.4 & 0.52 \\
PC1 & 3000 & 0 & 1158.72 & 3.44 \\
PC2 & 3000 & 0 & 1144.44 & 4.63 \\
EC1 & - & - & 0 & 100 \\
EPC1 & 833.55 & 72.215 & 490.05 & 59.15 \\
\hline
\end{tabular}




\section{Additional material}

Additional file 1: Supplementary Material. Additional file contains the supplementary data regarding recovery studies, robustness and solvent optimization.

\section{Author details}

${ }^{1}$ H.E.J. Research Institute of Chemistry, International Center for Chemical and Biological Sciences (ICCBS), University of Karachi, Karachi-75270, Pakistan. ${ }^{2}$ Department of Chemistry, University of Karachi, Karachi-75270, Pakistan.

\section{Authors' contributions}

SGM: Participated in the experimental designing and method optimization. UF: Performed the experiments. RS: Involved in the useful discussion and participated in designing experiment.

\section{Competing interests}

The authors declare that they have no competing interests.

Received: 5 November 2011 Accepted: 22 January 2012

Published: 22 January 2012

\section{References}

1. Adhiyaman $\mathrm{V}$, Vaishnavi A, Froese $\mathrm{S}$ : Hypersensitivity reaction to balsalazide. Brit Med J 2000, 320:613.

2. Bergh J, Jonsson PE, Glimelius B, Nygren P: Overview of chemotherapy effects in breast cancer. Acta Oncol 2001, 40:253-281.

3. Troy DB: Remington: The science and practice of pharmacy. 21 edition. Lippincott Williams \& Wilkins: Philadelphia, PA; 2006.

4. Hongxin $Y$ : Concurrent determination of chloramphenicol and prednisolone acetate in chloramphenicol and prednisolone acetate eye drops by HPLC. Chinese Pharma Affa 2007, 6:410-412.

5. Liping Z, Ming C, Shufang L: Forecasting of the shelf-life of chloramphenicol prednisolone acetum eye drop. China Pharmacist 2007 10:342-343.

6. Ma Q, Wang C, Wang X, Bai H, Chen W, Wu T, Zhou X, Yu W: Using ultra performance liquid chromatography. Chinese J Chromatogr 2007, 25:541-545.

7. Lunn G: HPLC methods for pharmaceutical analysis John Wiley \& Sons: New York, USA; 2000.

8. Wang L, Li YQ: Simultaneous determination of ten antibiotic residues in milk by UPLC. Chromatogr 2009, 70:253-258.

9. King S, Stoffolano PJ, Robinson E, Eichhold TE, Hoke SH II, Baker TR, Richardson EC, Wehmeyer KR: The evaluation and application of UPLC for the rapid analysis of dose formulation. Sep Sci Redefined 2005, 33-36.

10. Liu HL, Yang R, Li F, Ma YJ: Determination of seven antibiotics in cosmetics by ultra performance liquid chromatography. J Environ Health 2009, 26:453-454.

11. Liu HL, Li F, Yang R, Wang LH, Ma YJ: Determination of common antibiotics and metronidazole in cosmetics by ultra performance liquid chromatography-tandem mass spectrometry. Chinese J Chromatogr 2009, 27:50-53.

12. Al-Ashban RM, Rao RM, Khan ZA, Shah AH: A reverse phase HPLC method for the simultaneous determination of prednisolone, chloramphenicol and its degradation. J Saudi Chem Soc 2002, 6:399-408.

13. Sethi PD: HPTLC high performance thin layer chromatography quantitative analysis of pharmaceutical formulations CBS Publishers \& Distributors: New Delhi, India; 1996.

14. ICH Q2 (R1) Validation of analytical procedures: text and methodology. proceedings of the International Conference on Harmonization, 1995 [http:// www.ich.org/fileadmin/Public_Web_Site/ICH_Products/Guidelines/Quality/ Q2_R1/Step4/Q2_R1_Guideline.pdf].

15. ICH Q1A (R2) Stability testing of new drug substances and products. proceedings of the International Conference on Harmonization, 2003 [http:// www.ich.org/fileadmin/Public_Web_Site/ICH_Products/Guidelines/Quality/ Q1A_R2/Step4/Q1A_R2_Guideline.pdf].

16. US Pharmacopeia: In USP-31 NF 26. Volume 1719-20. The United States Pharmacopeial Convention: Maryland, USA; 2008:3065.
17. British Pharmacopoeia Commission: In British Pharmacopoeia 2010 Volume I and II. Volume 458. The Stationery Office: London, UK; 2010:1754.

doi:10.1186/1752-153X-6-7

Cite this article as: Musharraf et al:: Stress degradation studies and development of stability-indicating TLC-densitometry method for determination of prednisolone acetate and chloramphenicol in their individual and combined pharmaceutical formulations. Chemistry Central Journal 2012 6:7.

\section{Publish with ChemistryCentral and every scientist can read your work free of charge \\ "Open access provides opportunities to our colleagues in other parts of the globe, by allowing anyone to view the content free of charge." W. Jeffery Hurst, The Hershey Company. \\ - available free of charge to the entire scientific community \\ - peer reviewed and published immediately upon acceptance \\ - cited in PubMed and archived on PubMed Central \\ - yours - you keep the copyright \\ Submit your manuscript here: \\ http://www.chemistrycentral.com/manuscript/<smiles>c1ccccc1</smiles> ChemistryCentral}

